\title{
CORRECTION
}

View Article Online

View Journal | View Issue

\section{Correction: Structural, optical, and electronic studies of wide-bandgap lead halide perovskites}

Cite this: J. Mater. Chem. C, 2015 3, 9480

DOI: $10.1039 / \mathrm{c} 5 \operatorname{tc} 90155 \mathrm{c}$

www.rsc.org/MaterialsC

\author{
Riccardo Comin, ${ }^{a}$ Grant Walters, ${ }^{a}$ Emmanuel Sol Thibau, ${ }^{\mathrm{b}}$ Oleksandr Voznyy, ${ }^{a}$ \\ Zheng-Hong Lu ${ }^{b}$ and Edward H. Sargent*a
}

Correction for 'Structural, optical, and electronic studies of wide-bandgap lead halide perovskites' by Riccardo Comin et al., J. Mater. Chem. C, 2015, 3, 8839-8843.

There are two errors on the second page of this article. The first concerns the sentence "The monotonic trend in the lattice constant, which increases by $\sim 5 \%$ from $\mathrm{MAPbBr}_{3}$ to $\mathrm{MAPbCl}_{3}$, confirms the progressive expansion of the unit cell." which should read "The monotonic trend in the lattice constant, which increases by $\sim 5 \%$ from $\mathbf{M A P b C l}_{3}$ to $\mathbf{M A P b B r}_{3}$, confirms the progressive expansion of the unit cell." The second error concerns the plot in Fig. 1b, the correct version of this figure is as follows:
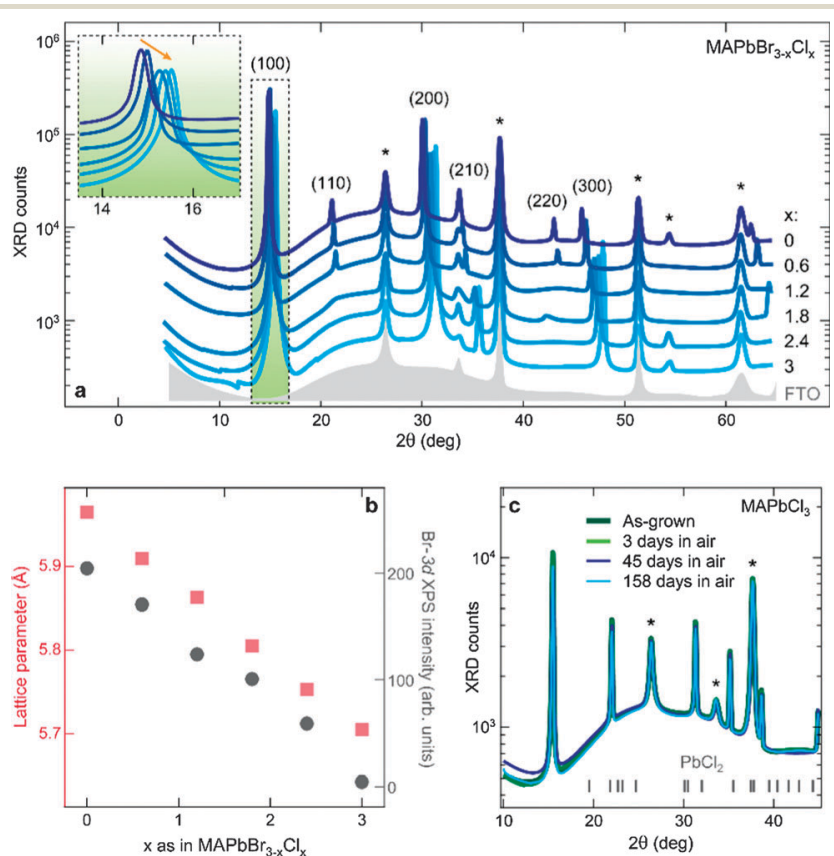

Fig. 1 (a) X-ray diffraction scans of $\mathrm{Pb}(\mathrm{Ac})_{2}$-based thin films of $\mathrm{MAPbBr}_{3-x} \mathrm{Cl}_{x}$ (continuous lines) on fluorine-doped tin oxide (FTO). Shaded area: background signal from a pure FTO substrate (corresponding peaks are marked with a star). Inset: magnified view of the (100) diffraction peak. (b) Evolution of the lattice parameter and $\mathrm{Br}-3 \mathrm{~d}$ peak intensity vs. $x$. (c) XRD pattern of $\mathrm{PbCl}_{2}-$ based $\mathrm{MAPbCl}_{3}$ over time, demonstrating structural stability of pure- $\mathrm{Cl}$ films in ambient conditions. The bottom bars mark the angular position of the powder XRD peaks in $\mathrm{PbCl}_{2}$.

The Royal Society of Chemistry apologises for these errors and any consequent inconvenience to authors and readers.

\footnotetext{
${ }^{a}$ Department of Electrical and Computer Engineering, University of Toronto, 10 King’s College Road, Toronto, Ontario, M5S 3G4, Canada. E-mail: ted.sargent@utoronto.ca

${ }^{b}$ Department of Materials Science and Engineering, University of Toronto, 184 College Street, Toronto, Ontario M5S 3E4, Canada
} 